\title{
Dermatology
}

\section{Splice Site Mutations in the P-Cadherin Gene Underlie Hypotrichosis with Juvenile Macular Dystrophy}

\author{
Y. Shimomura ${ }^{a} \quad$ M. Wajid $^{\mathrm{a}} \quad$ M. Kurban ${ }^{\mathrm{a}}$ A.M. Christiano ${ }^{\mathrm{a}, \mathrm{b}}$ \\ Departments of a Dermatology and ${ }^{b}$ Genetics and Development, Columbia University, New York, N.Y., USA
}

\section{Key Words}

Hypotrichosis - Macular dystrophy • Ectrodactyly •

P-cadherin

\begin{abstract}
Background: Hypotrichosis with juvenile macular dystrophy (HJMD; OMIM 601553) is a rare autosomal recessive disorder characterized by hypotrichosis with short scalp hair and progressive macular dystrophy leading to blindness between the second and the fourth decades of life. HJMD is caused by mutations in the $\mathrm{P}$-cadherin gene $(\mathrm{CDH} 3)$, a member of the family of classical cadherins. Methods: We analyzed the DNA from members of 2 consanguineous Pakistani families with HJMD for mutations in the P-cadherin gene through direct sequencing. Results: We identified 2 splice site mutations in the P-cadherin gene in these families. One was a novel mutation, Ivs12-2A $\rightarrow G$ and the other a recurrent mutation, Ivs10-1G $\rightarrow$ T. A screening assay for the novel mutation ruled out the possibility of a polymorphism. Using haplotype analysis, we determined that the mutation, Ivs10-1G $\rightarrow T$, is a founder mutation in the Pakistani population. Conclusion: We identified 2 splice site mutations in the $C D H 3$ gene leading to HJMD, further enriching our understanding of HJMD versus ectodermal dysplasia, ectrodactyly and macular dystrophy syndrome.

Copyright @ 2010 S. Karger AG, Basel
\end{abstract}

\section{Introduction}

Hypotrichosis with juvenile macular dystrophy (HJMD) is a rare autosomal recessive disorder that is characterized clinically by short scalp hair since birth in association with progressive macular degeneration, leading to blindness between the second and fourth decades of life. The cadherin-3 (CDH3) gene, encoding P-cadherin, has been implicated in the pathogenesis of HJMD [1]. P-cadherin is a major component of the adherens junction in several tissues [2]. It is composed of 5 extracellular domains, designated EC1-EC5, a transmembrane domain and a small intracellular domain [3]. The extracellular domains, mainly EC1, are crucial to the normal alignment of the protein in order to form the appropriate adhesive interactions with nearby cells [4]. The EC domains contain calcium-binding regions that are imperative for their normal functioning [4]. The intracellular domain of P-cadherin interacts with $\beta$-catenin, which binds, indirectly through $\alpha$-catenin, to the actin filament-binding proteins and other actin-binding proteins and functions in maintaining the cytoskeleton of the cells

Institute where the work was performed: Columbia University.

\section{KARGER}

두 2010 S. Karger AG, Basel

Fax +41613061234

E-Mail karger@karger.ch

www.karger.com
Accessible online at:

www.karger.com/drm
Angela M. Christiano, $\mathrm{PhD}$

Department of Dermatology, Columbia University

College of Physicians and Surgeons, 630 West 168th Street VC-1526

New York, NY 10032 (USA)

Tel. +1 212305 9565, Fax +1 212305 7391, E-Mail amc65@ columbia.edu 


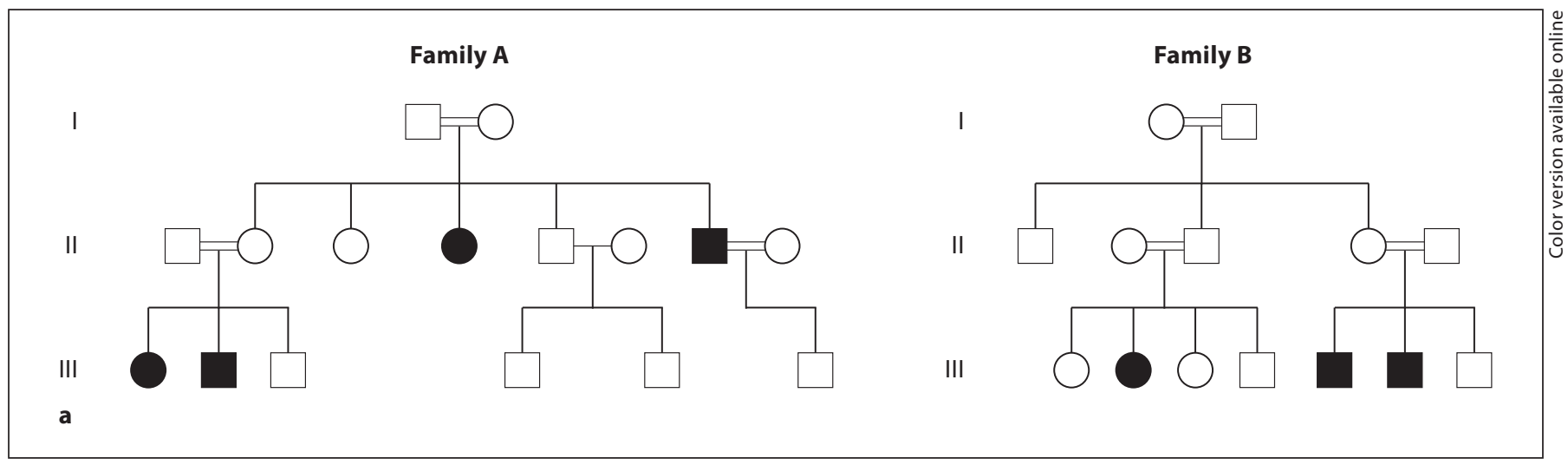

Fig. 1. a Pakistani families with HJMD showing an autosomal recessive pattern of inheritance. $\mathbf{b}$ A patient from family A with the splice site mutation Ivs12-2A $\rightarrow \mathrm{G}$ showing evidence of generalized hypotrichosis. This patient is in his fourth decade. c A 10 -year-old boy from family B with the splice site mutation Ivs10-1G $\rightarrow$ T showing scalp hypotrichosis. This patient reported progressive vision loss.
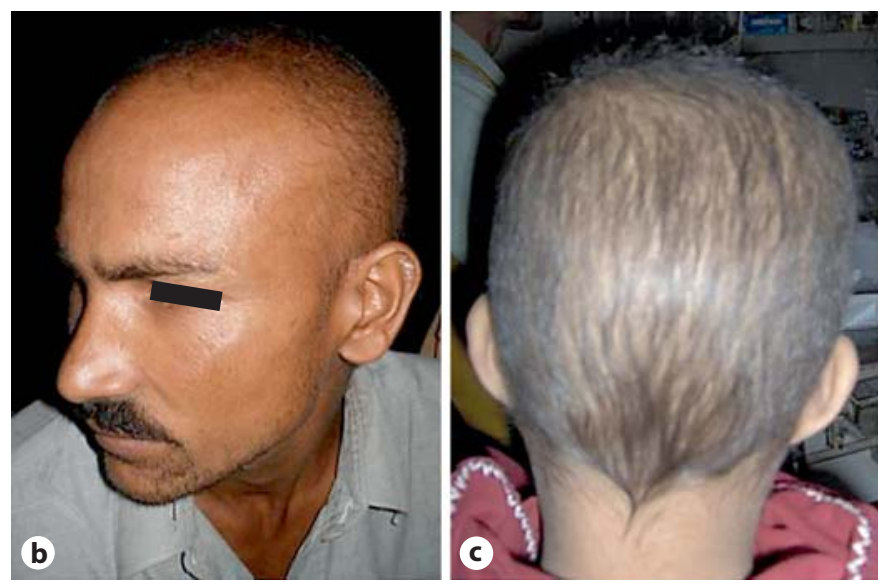

[5]. More importantly, $\beta$-catenin is involved in the Wnt signaling pathway, influencing many developmental processes [6]. The function of P-cadherin is not restricted to the formation of adherens junctions but is also involved in other biological processes, such as cell recognition, cell signaling, morphogenesis and tumor development [7].

Paradoxically, mutations in $\mathrm{CDH} 3$ can also lead to the development of a distinct syndrome known as ectodermal dysplasia, ectrodactyly and macular dystrophy (EEM) [8]. EEM has a similar presentation to HJMD including the additional feature of ectrodactyly with split hand and foot malformation. Intriguingly, an identical mutation in $\mathrm{CDH} 3$ can lead to EEM in some patients but normal limb development in HJMD patients, suggesting a role for modifier genes in defining the phenotype [8]. All members of the same family will either have ectrodactyly or show normal limb development, although the severity of ectrodactyly can be variable within a family, suggesting a modifier gene may be closely linked to $\mathrm{CDH} 3$.

To date, only a few mutations have been identified in $\mathrm{CDH} 3$ in either EEM or HJMD. Here, we report 2 mutations in $\mathrm{CDH} 3$ in $\mathrm{HJMD}$ families from Pakistan, further extending the spectrum of mutations in $\mathrm{CDH} 3$.

\section{Materials and Methods}

DNA Extraction

After obtaining informed consent, we collected peripheral blood samples from family members and 50 population-matched unrelated unaffected individuals in EDTA-containing tubes under institutional approval and in adherence to the Declaration of Helsinki Principles. Genomic DNA was isolated from these samples according to standard techniques.

\section{Mutation Analysis}

All exons of $C D H 3$ with adjacent sequences of exon-intron borders were amplified by PCR with primers and conditions described previously [8]. The amplified PCR products were directly sequenced in an ABI Prism 310 Automated Sequencer, using the ABI Prism Big Dye Terminator Cycle Sequencing Ready Reaction Kit (PE Applied Biosystems).

Dermatology 2010;220:208-212 


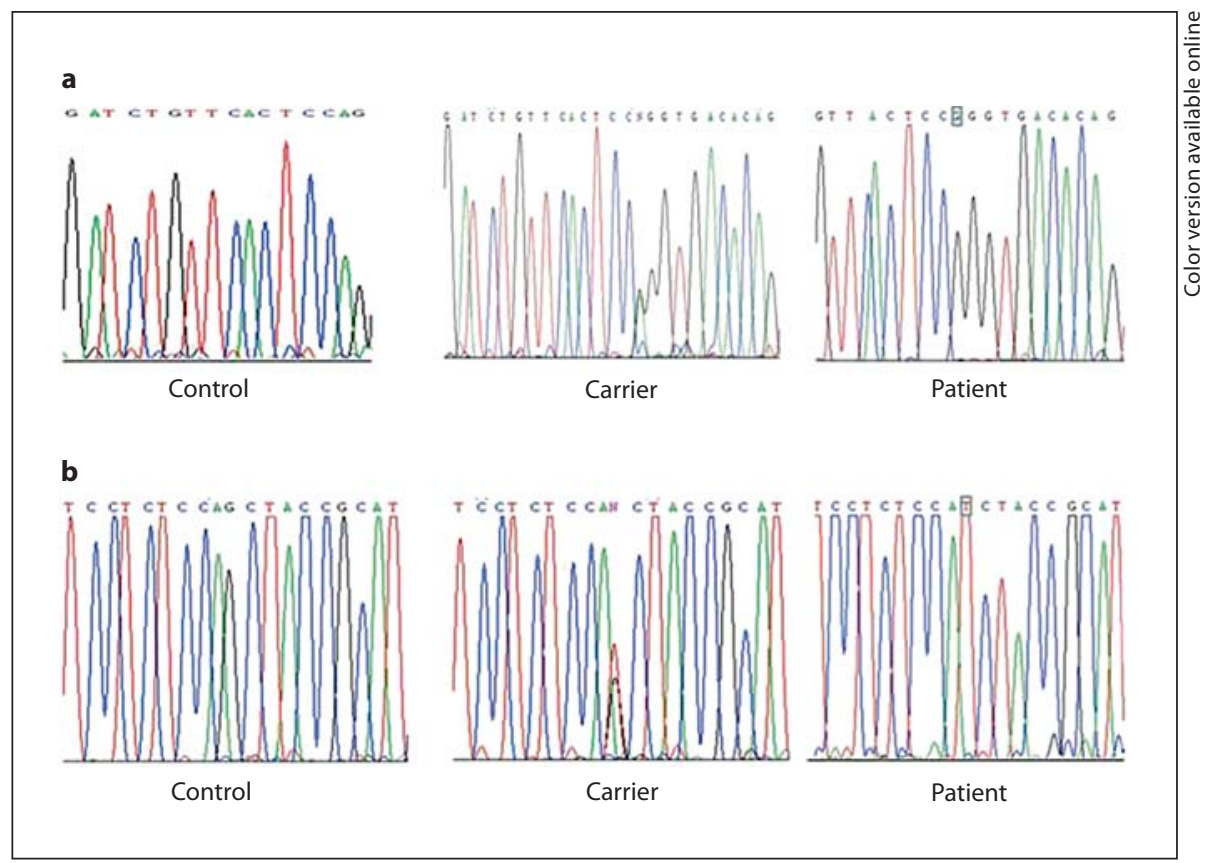

Fig. 2. a All affected individuals in family A were homozygous for the novel splice site mutation Ivs12-2A $\rightarrow \mathrm{G}$. The unaffected individuals were either heterozygous for the mutation or carried both wild-type alleles (the site of mutation is boxed). $\mathbf{b}$ The affected individuals from family $B$ were homozygous for the recurrent splice site mutation Ivs10-1G $\rightarrow \mathrm{T}$. The unaffected individuals were either heterozygous or carried both wild-type alleles (the site of mutation is boxed). c Haplotype analysis performed on members of family $B$ and another family that we had previously reported with the same mutation [9] revealed that Ivs10-1G $\rightarrow$ T is a founder mutation in the Pakistani population.

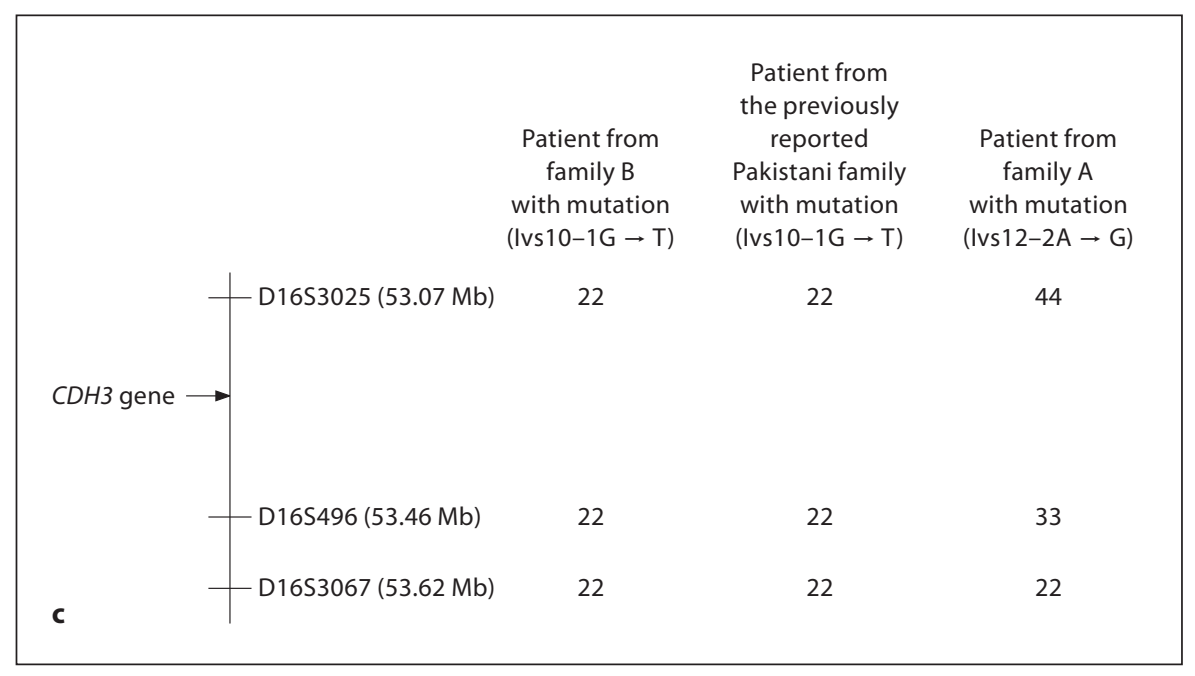

\section{Haplotype Analysis}

In order to determine whether the mutation Ivs $10-1 \mathrm{G} \rightarrow \mathrm{T}$ was a founder mutation in the Pakistani population, genomic DNA from affected individuals in family B and a different Pakistani family that we had previously reported with the same mutation [9] were amplified using 3 known microsatellite markers (D16S3025, D16S496 and D16S3067) spanning CDH3. The amplification conditions for each PCR were $94^{\circ} \mathrm{C}$ for $2 \mathrm{~min}$, followed by 35 cycles of $94^{\circ} \mathrm{C}$ for $30 \mathrm{~s}, 55^{\circ} \mathrm{C}$ for $30 \mathrm{~s}$ and $72^{\circ} \mathrm{C}$ for $30 \mathrm{~s}$, with a final extension at $72^{\circ} \mathrm{C}$ for $7 \mathrm{~min}$. The amplified PCR products were run on an $8 \%$ polyacrylamide gel and analyzed by visual inspection.

\section{Results}

\section{Patients}

The pattern of inheritance in both Pakistani families (families A and B) was autosomal recessive (fig. 1a). By history, the patients and family members reported that they had short hair with decreased density since birth, with progressively weak eye sight starting in the second half of the first decade, leading to complete loss of vision between the second and fourth decades of life. On physical examination, the patients had generalized scalp hypotrichosis and severe visual impairment and blindness 
which was more evident in older family members (fig. 1b). None of the patients had limb deformities found in EEM syndrome.

\section{Genetic Analysis}

A homozygous splice site mutation affecting the donor splice site of intron 12 , Ivs $12-2 \mathrm{~A} \rightarrow \mathrm{G}$, was identified in all affected individuals of family A (fig. 2a). Unaffected individuals were either heterozygous for the mutation or carried 2 wild-type alleles. Screening assays with the restriction enzyme MspI confirmed that 50 control individuals did not carry the mutation (data not shown).

Mutation analysis in the second family revealed a homozygous splice site mutation involving the acceptor splice site of intron 10, Ivs10-1G $\rightarrow \mathrm{T}$, in all affected individuals (fig. 2b). Haplotype analysis showed that the mutation Ivs10-1G $\rightarrow T$ is a founder mutation in the Pakistani population (fig. 2c).

\section{Discussion}

Classical and desmosomal cadherins are among the 2 major proteins contributing to cell-cell junctions in several organs including the skin. Abnormalities in both classes of cadherins have been shown to be linked to several hair abnormalities presenting as an isolated finding or as part of syndromes. Among these components are plakoglobin and desmoplakin, which underlie the Naxos and Carvajal syndromes, respectively, and result in woolly hair $[10,11]$. Mutations in DSG4 and corneodesomin $(C D S N)$, contributing to cell-cell adhesion, result in isolated autosomal recessive and dominant hypotrichosis, respectively $[12,13]$. More recently, desmocollin-3 mutations have been related to hypotrichosis in association with generalized blistering [14]. P-cadherin is a major component of the classical cadherins and cell-cell adhesion and is highly expressed in the hair follicle placode during embryogenesis and the matrix region in postnatal hair follicles $[15,16]$, consistent with the hypotrichosis observed in the setting of HJMD and EEM.

Hypotrichosis and macular dystrophy are common features of both HJMD and EEM. However, a striking difference is the presence of ectrodactyly/split hand and foot malformation in EEM. Moreover, the identical mutation in different patients gives rise to both phenotypes [8], raising the possibility of modifier genes influencing disease expressivity. The fact that the 2 phenotypes are mutually exclusive in families suggests that the modifier must be closely linked to $\mathrm{CDH}$. P-cadherin and E-cad- herin reside close together (within $\mathrm{kb}$ ) on human chromosome 16 and are expected to cosegregate unless rare recombination events occur. Similarly to P-cadherin, Ecadherin is also a classical cadherin, and therefore it is possible that E-cadherin may be one of the modifier genes via compensation. Recently, we have shown in mice that during limb development, both P- and E-cadherin are coexpressed in the apical epidermal ridge [9]. Our results suggested a modifier role for E-cadherin which might explain why some patients with $\mathrm{P}$-cadherin mutations have normal limb development. In contrast, an overlap of Pand E-cadherin expression is not seen in the hair follicle or the retina. In the hair follicle, initially E-cadherin expression is elevated, but as the placode starts to form, the E-cadherin levels drop markedly and P-cadherin concomitantly increases [15]. The downregulation of E-cadherin and the overexpression of P-cadherin persist throughout hair follicle development [17]. P-cadherin is also implicated in development of the eye, in particular the retinal pigmented epithelium, while E-cadherin is expressed in the corneal epithelium [18]. Therefore, in contrast to the limb, E-cadherin cannot substitute for P-cadherin in hair follicle and retina, which may explain why all patients with $\mathrm{P}$-cadherin will have combined hypotrichosis and macular dystrophy while only some have ectrodactyly/split hand and foot malformation.

In this study, we identified a novel acceptor splice site mutation, Ivs12-2A $\rightarrow \mathrm{G}$, in intron 12 of $\mathrm{CDH} 3$ in family A that is predicted to lead to an in-frame skipping of exon 13 , which is $207 \mathrm{bp}$ in size. At the protein level, it is most likely to result in a truncated protein lacking 69 amino acid residues which correspond to the EC5 domain and a part of the transmembrane domain. Since the EC5 domain plays an important role in cell-cell adhesion, and the transmembrane domain is critical to membrane localization, the truncated protein would severely perturb the function of the P-cadherin protein.

We identified a second acceptor splice site mutation, Ivs10-1G $\rightarrow \mathrm{T}$, in intron 10 of $\mathrm{CDH} 3$ in family $\mathrm{B}$ that is predicted to result in an out-of-frame skipping of exon 11, which is $146 \mathrm{bp}$ in size, and leads to a premature termination codon (p.Ser475ArgfsX16). The majority of mRNA from the mutant allele would be degraded through nonsense-mediated mRNA decay. Alternatively, a nonfunctional, truncated protein could be produced. We [9] and others [19] previously identified this identical mutation in other Pakistani families with HJMD. To determine whether it is a founder mutation, we compared the haplotype using microsatellite markers close to $\mathrm{CDH} 3$ between affected individuals in family $\mathrm{B}$ and the family that 
we had previously reported [9]. Both families showed the same disease-related haplotype, suggesting that Ivs10$1 \mathrm{G} \rightarrow \mathrm{T}$ is a common founder mutation in Pakistani populations.

In conclusion, our awareness of HJMD should be considered in the differential diagnosis of early-onset hypotrichosis, and subsequent regular eye examinations should be performed if the diagnosis of HJMD is made. Our findings shed further light on the allelic spectrum of mutations underlying HJMD.

\section{Acknowledgements}

We gratefully acknowledge the families for having participated in this study. We also thank Helen Lam for her expert technical assistance. This study was supported in part by a Research Career Development Award from the Dermatology Foundation (to Y.S.) and an NIH grant from USPHS, NIH/NIAMS RO1 AR44924 (to A.M.C.).

\section{References}

1 Sprecher E, Bergman R, Richard G, et al: Hypotrichosis with juvenile macular dystrophy is caused by a mutation in $\mathrm{CDH} 3$, encoding P-cadherin. Nat Genet 2001;29:134-136.

-2 Shimoyama Y, Yoshida T, Terada M, et al: Molecular cloning of a human Ca2+-dependent cell-cell adhesion molecule homologous to mouse placental cadherin: its low expression in human placental tissues. J Cell Biol 1989; 109:1787-1794.

-3 Yagi T, Takeichi M: Cadherin superfamily genes: functions, genomic organization, and neurologic diversity. Genes Dev 2000;14: 1169-1180.

4 Chen CP, Posy S, Ben-Shaul A, et al: Specificity of cell-cell adhesion by classical cadherins: critical role for low-affinity dimerization through $\beta$-strand swapping. Proc Natl Acad Sci USA 2005;102:8531-8536.

$\checkmark 5$ Patel SD, Ciatto C, Chen CP, et al: Type II cadherin ectodomain structures: implications for classical cadherin specificity. Cell 2006;124:1255-1268.

-6 Linker C, Lesbros C, Gros J, et al: $\beta$-Catenindependent Wnt signalling controls the epithelial organisation of somites through the activation of paraxis. Development 2005; 132:3895-3905
7 Goodwin M, Yap AS: Classical cadherin adhesion molecules: coordinating cell adhesion, signaling and the cytoskeleton. J Mol Histol 2004;35:839-844.

$\checkmark 8$ Kjaer KW, Hansen L, Schwabe GC, et al: Distinct $\mathrm{CDH} 3$ mutations cause ectodermal dysplasia, ectrodactyly, macular dystrophy (EEM syndrome). J Med Genet 2005;42:292298.

9 Shimomura Y, Wajid M, Shapiro L, Christiano AM: P-cadherin is a p63 target gene with a crucial role in the developing human limb bud and hair follicle. Development 2008;135: 743-753.

10 McKoy G, Protonotarios N, Crosby A, et al: Identification of a deletion in plakoglobin in arrhythmogenic right ventricular cardiomyopathy with palmoplantar keratoderma and woolly hair (Naxos disease). Lancet 2000; 355:2119-2124.

11 Norgett EE, Hatsell SJ, Carvajal-Huerta L, et al: Recessive mutation in desmoplakin disrupts desmoplakin-intermediate filament interactions and causes dilated cardiomyopathy, woolly hair and keratoderma. Hum Mol Genet 2000;9:2761-2766.

12 Kljuic A, Bazzi H, Sundberg JP, et al: Desmoglein 4 in hair follicle differentiation and epidermal adhesion: evidence from inherited hypotrichosis and acquired pemphigus vulgaris. Cell 2003;113:249-260.
13 Levy-Nissenbaum E, Betz RC, Frydman M, et al: Hypotrichosis simplex of the scalp is associated with nonsense mutations in CDSN encoding corneodesmosin. Nat Genet 2003;34:151-153.

14 Ayub M, Basit S, Jelani M, et al: A homozygous nonsense mutation in the human desmocollin-3 (DSC3) gene underlies hereditary hypotrichosis and recurrent skin vesicles. Am J Hum Genet 2009;85:515-520.

15 Jamora C, DasGupta R, Kocieniewski P, Fuchs E: Links between signal transduction, transcription and adhesion in epithelial bud development. Nature 2003;422:317-322.

16 Bergman R, Sapir M, Sprecher E: Histopathology of hypotrichosis with juvenile macular dystrophy. Am J Dermatopathol 2004;26: 205-209.

17 Muller-Rover S, Tokura Y, Welker P, et al: $\mathrm{E}$ - and $\mathrm{P}$-cadherin expression during murine hair follicle morphogenesis and cycling. Exp Dermatol 1999;8:237-246.

$\checkmark 18$ Xu L, Overbeek PA, Reneker LW: Systematic analysis of $\mathrm{E}$-, $\mathrm{N}$ - and $\mathrm{P}$-cadherin expression in mouse eye development. Exp Eye Res 2002;74:753-760.

19 Jelani M, Salman Chishti M, Ahmad W: A novel splice-site mutation in the $\mathrm{CDH} 3$ gene in hypotrichosis with juvenile macular dystrophy. Clin Exp Dermatol 2009;34:68-73. 